\title{
Analysis of cracked steel members reinforced by pre-stress composite patch
}

\author{
P. COLOMBI ${ }^{1}$, A. BASSETTI ${ }^{2}$ and A. NUSSBAUMER ${ }^{2}$ \\ ${ }^{\prime}$ Department of Structural Engineering, Milan Tecbnical University, Piazza L. da Vinci, 32, 20133 Milan, Italy, ${ }^{2}$ Institute of Steel Construction, Swiss \\ Federal Institute of Technology, EPFL Lausanne, Switzerland
}

Received in final form 6 August 2002

\begin{abstract}
Pre-stress bonded composite patch is a promising technique to reinforce steel member damaged by fatigue. The effectiveness of this technique was verified by fatigue tests on notched steel plates. Results showed that the application of carbon fibre reinforced plastic (CFRP) strips and, eventually, the introduction of a compressive stress by pretension of the CFRP strips prior to bonding produced a significant increment of the remaining fatigue life. In this paper, the stress intensity factor in the notched plates is computed by a two-dimensional finite element model in connection with the three-layer technique in order to reduce the computational effort. Due to high stress concentration at the plate crack tip, debond is assumed at the adhesive-plate interface. The goal is to illustrate the influence of some reinforcement parameters such as the composite strip stiffness, the pre-stress level, the adhesive layer thickness and the size of the debonded region on the effectiveness of the composite patch reinforcement.
\end{abstract}

Keywords composite patch; fatigue crack reinforcement; parametric analysis.

In Bassetti ${ }^{5}$ a novel technique was proposed to reinforce steel member damaged by fatigue. It consists in the application of carbon fibre reinforced plastic (CFRP) strips and, eventually, the introduction of a compressive stress by pretension of CFRP strips prior to bonding. Note that this new methodology applied to riveted steel members avoids the drawbacks of standard reinforcement techniques such as hole drilled at crack front, cover plates application, replacement of rivets by high strength bolts, cold expansion of the rivet hole and welding of the detected cracks. ${ }^{1}$ As a step towards the validation of this technique, fatigue tests on notched steel plate reinforced by CFRP strips were performed in Bassetti et $a l^{4}$ This technique is particularly appealing for the fatigue life extension of old riveted steel bridges built up at the beginning of the last century by non-weldable steel. Experimental tests were then performed in Bassetti et $a l^{4}$ on a 91-year-old-cross girder in order to prove the

Correspondence: P. Colombi department of Structural Engineering, Milan Technical University, Piazza L. da Vinci, 32,20133 Milan, Italy. E-mail: colombi@stru.polimi.it effectiveness of pre-stress CFRP-strips to stop fatigue crack emanating from the rivet hole or to prevent further cracking at other locations.

The carbon fibre reinforced plastic laminates have physical and mechanical properties particularly interesting for reinforcement of fatigue damaged steel elements. The high fatigue resistance of CFRP avoids crack propagation from the cracked steel section into the patch. The high stiffness of CFRP reduces the stress range in the cracked steel section and promotes crack bridging. The high tensile strength of CFRP allows also the application of a pretension to composite strips in order to increase the effectiveness of the bonded patch on thicker steel section. Finally, the low self-weight of CFRP plates limits the dead load increment and simplifies the strengthening operations. Composite patch reinforcement technique is a standard and reliable procedure in different engineering branches to reinforce structural elements subjected to extreme actions (high fatigue loads, high temperature ranges and exposure to aggressive agents) and nowadays, is also a standard reinforcement methodology in aircraft industries. ${ }^{7}$ In fact the CFRP laminates is becoming a familiar procedure for 
the strengthening and rehabilitation of the reinforced concrete bridges (Meier, 1995). ${ }^{8}$ The CFRP-laminates, eventually, could be pre-stressed ${ }^{9}$ in order to increase the reinforcement effectiveness. Some attempts were also done $^{10}$ to increase the load carrying capacity of steel bridges.

In this paper, reference is made to the notched steel plates tested in Bassetti et al. ${ }^{5}$ The goal is to investigate numerically the effect of CFRP-strips' stiffness, adhesive thickness, pre-stress level and debond size region on the stress intensity factor, the parameter governing crack propagation rate and then fatigue lifetime. To this end, a finite element model is developed and is based on the Mindlin plate theory in order to reduce the computational effort connected to a full three-dimensional analysis. ${ }^{11}$

\section{EXPERIMENTAL EVIDENCE}

The effectiveness of pre-stressed CFRP-plates to arrest the crack propagation was investigated (Fig. 1) on notched steel plates. ${ }^{4}$ The central notch consists in a hole and two initial traversing cracks produced by electroerosion. The plates were reinforced on both sides by two unidirectional pultruded carbon fibre sheets with width of $50 \mathrm{~mm}$ as shown in Fig. 1. A two-component viscous epoxy was used for bonding the laminate to the steel plate. All the specimens were tested under constant amplitude tensile loading (no thermal stresses are then considered) using a stress range $\Delta \sigma_{y}=80 \mathrm{MPa}$ and a stress ratio $R=\sigma_{y, \min } / \sigma_{y, \max }=0.4$ in the nominal section of the un-reinforced specimen. Tests were performed on a hydraulic testing machine with a dynamic capacity of $800 \mathrm{kN}$. As is well known, the fatigue crack propagation is controlled by the stress intensity factor range
$\Delta K=\Delta \sigma_{y} \cdot Y(a) \cdot \sqrt{\pi \cdot a}$ and the stress ratio $R$. A lower stress ratio in fact promotes crack closure that reduces crack growth rate. ${ }^{12}$ The crack length and the crack growth measurements were carried out using the electric potential drop method. Results of the fatigue tests are shown in the crack length to number of cycles diagram of Fig. 2 where the reference tests are given by the un-reinforced steel plates. Composite patch acts on the notched plate in three different ways. First, it lessens the stress range $\Delta \sigma_{y}$ at crack tip, second it reduces the corrector factor $Y(a)$ by bridging the crack lips

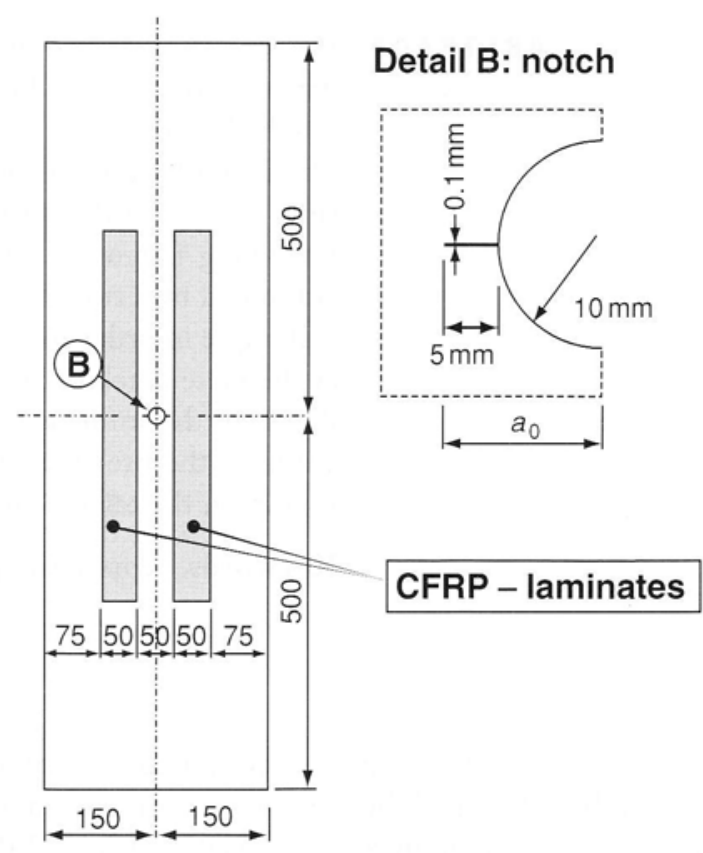

Fig. 1 Notched steel plate specimen.

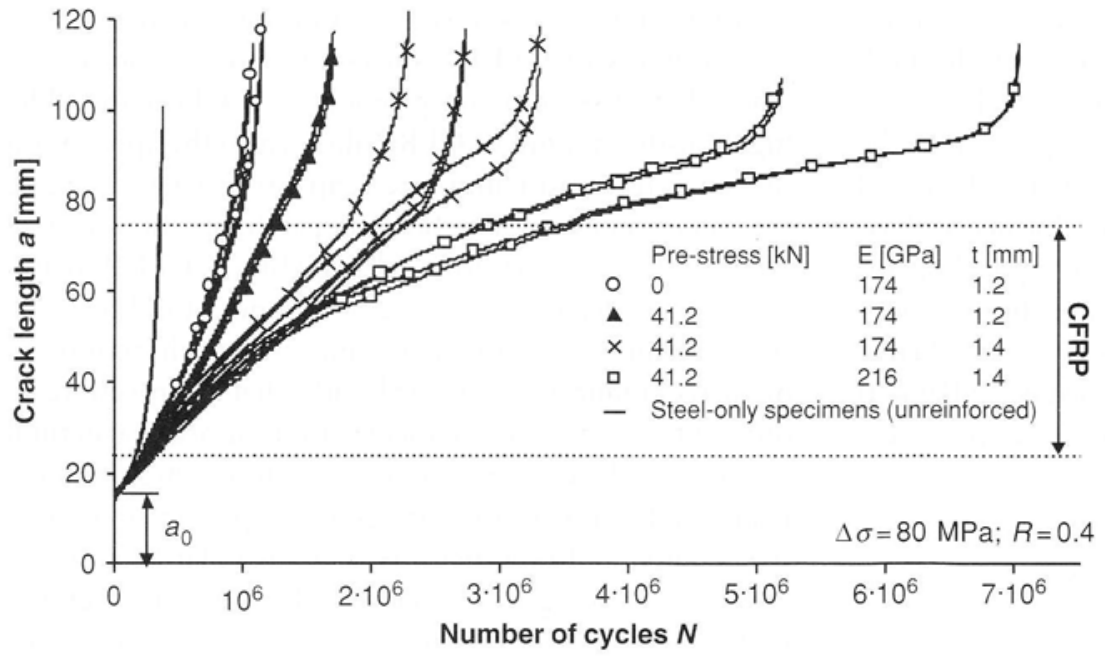

Fig. 2 Crack length vs. number of cycles for different patch configuration. 
and third the compressive stress field produced by the pretension of composite patch reduces the stress ratio $R$ and then promotes crack closure.

By reinforcing the steel plates with non-pre-stress CFRP strips with mean Young's modulus in the fibres direction $E_{1}=174 \mathrm{GPa}$ and thickness $h_{\mathrm{c}}=1.2 \mathrm{~mm}$, fatigue life of specimens is increased by a factor of about three. If the composite strips are pre-stress prior to bonding by applying a tensile stress equal to $632 \mathrm{MPa}$ in the CFRP cross-section, the fatigue life is increased by a factor of about five. Even longer fatigue life was achieved by stiffer CFRP-strips $\left(E_{1}=216 \mathrm{GPa}\right.$ and $b_{\mathrm{c}}=1.4 \mathrm{~mm}$ ) with the same pre-stress level as before. With this reinforcement, configuration of the fatigue life is increased by a factor of about 16 . As the crack approaches the interior boundary of the patch, high stress concentration at the crack tip produces debond at the plate-adhesive or adhesive-patch interface. From the inspection of the failed specimens, it was concluded that debond was present between the steel plate and the adhesive layer. Debond was also investigated by Optical Speckle Interferometry technique. ${ }^{13,6}$ It was found in Bassetti et al. ${ }^{6}$ that an elliptical debond with an aspect ratio $c / b$ equal to $1 / 5$ produced a displacement field, which fitted well in the experimental one.

\section{FINITE ELEMENT MODEL}

One of the main aspects of bonded composite reinforcement technology is the stress analysis of the reinforced structure and the consequent stress intensity factor evaluation. Three-dimensional finite element analyses ${ }^{11}$ of composite patch repair have been conducted in the literature. Since the thickness of the adhesive is much smaller than the plate and composite patch one, a three dimensional model becomes very expensive due to the large number of elements required across the thickness to get acceptable aspect ratios in the adhesive layer. A number of two-dimensional finite element models were then employed in the literature to reduce the computational effort. ${ }^{11}$

In Ratwani et al. ${ }^{14}$ analyses were conducted by plain stress two-dimensional elements to model the cracked plate and composite patch. Shear spring elements were used to represent the adhesive. In Sun et al. ${ }^{15}$ twodimensional Mindlin plate elements with transverse shear deformation capability were used to model both the cracked plate and the composite patch. Again shear spring elements were introduced to represent the adhesive. The shear springs were connected to the cracked plate and the composite patch through displacement constraint equations, which satisfy the Mindlin plate assumptions. In Naboulsi et al. ${ }^{16}$ the three-layer technique was proposed to model a composite bonded reinforcement of a cracked plate. This technique uses two-dimensional finite element analysis, consisting of three layers, to model the cracked plate, adhesive and composite patch. It is not required to replace the adhesive layer by shear spring elements (noncontinuum body) since the adhesive is modelled as an elastic continuum medium. In this way the characteristics of the adhesive required to model nonlinear material behaviour are also captured. Constraints are used to enforce the compatibility along the plate-adhesive and the adhesive-patch interface based on Mindlin assumptions ${ }^{2}$ (Fig. 3).

The Mindlin plate theory assumes linear displacement field in the plate thickness. In the three layers technique, all three layers, cracked plate, adhesive and composite patch, are assumed to have a linear displacement field along the thickness and they satisfy the relations: ${ }^{16}$

$$
\begin{array}{ccc}
u^{\mathrm{c}}=u_{P}+\varphi_{y}^{P} \cdot z^{\mathrm{c}} & u^{\mathrm{a}}=u_{f}+\varphi_{y}^{7} \cdot z^{\mathrm{a}} & u^{\mathrm{s}}=u_{A}+\varphi_{y}^{A} \cdot z^{\mathrm{s}} \\
v^{\mathrm{c}}=v_{P}-\varphi_{x}^{P} \cdot z^{\mathrm{c}} & v^{\mathrm{a}}=v_{f}-\varphi_{x}^{7} \cdot z^{\mathrm{a}} & v^{\mathrm{s}}=v_{A}-\varphi_{x}^{A} \cdot z^{\mathrm{s}} \\
w^{\mathrm{c}}=w_{P} & w^{\mathrm{a}}=w_{f} & w^{\mathrm{s}}=w_{A}
\end{array}
$$

where the superscript s, a and c are used to denote the steel plate, adhesive layer and composite patch, respectively. The co-ordinates $z^{\mathrm{c}}, z^{\mathrm{a}}$ and $z^{\mathrm{s}}$ are measured from the midplane of each layer. At the plate-adhesive interface, where the $z$ co-ordinates for the cracked plate and the adhesive are equal, and at the adhesive-composite patch interface, where the $z$ co-ordinates for the adhesive and the composite patch are equal, the constraint equations reduce to: ${ }^{2}$

$$
\begin{aligned}
u^{\mathrm{a}} & =u^{\mathrm{s}} \Rightarrow u_{f}-u_{A}-\varphi_{y}^{f} \cdot \frac{b^{\mathrm{a}}}{2}-\varphi_{y}^{A} \cdot \frac{b^{\mathrm{s}}}{2}=0 \\
v^{\mathrm{a}} & =v^{\mathrm{s}} \Rightarrow v_{f}-v_{A}+\varphi_{x}^{7} \cdot \frac{b^{\mathrm{a}}}{2}+\varphi_{x}^{A} \cdot \frac{b^{\mathrm{s}}}{2}=0 \\
w^{\mathrm{a}} & =w^{\mathrm{s}}
\end{aligned}
$$

at the plate-adhesive interface and:

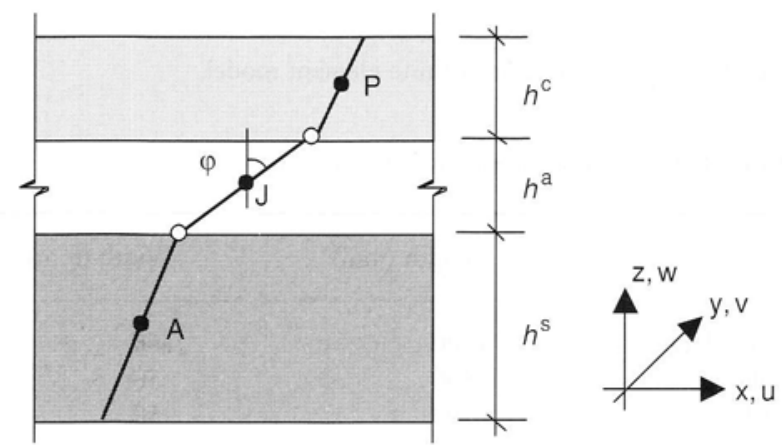

Fig. 3 Modelling of bonded reinforcement and necessary constraints at the interfaces. 


$$
\begin{aligned}
u^{\mathrm{c}} & =u^{\mathrm{a}} \Rightarrow u_{P}-u_{f}-\varphi_{y}^{P} \cdot \frac{b^{\mathrm{c}}}{2}-\varphi_{y}^{7} \cdot \frac{b^{\mathrm{a}}}{2}=0 \\
v^{\mathrm{c}} & =v^{\mathrm{a}} \Rightarrow v_{P}-v_{f}+\varphi_{x}^{P} \cdot \frac{b^{\mathrm{c}}}{2}+\varphi_{x}^{7} \cdot \frac{b^{\mathrm{a}}}{2}=0 \\
w^{\mathrm{c}} & =w^{\mathrm{a}}
\end{aligned}
$$

at the adhesive-patch interface. In the debonded region between the steel plate and the adhesive layer, the layers are independent of each other and the constraint equations are no longer valid. Note that due to the symmetry of the reinforcement no overlapping due to translation in the thickness direction is possible.

\section{STRESS INTENSITY FACTOR EVALUATION}

\section{Numerical model}

The commercial finite element code $\mathrm{ABAQUS}^{\circledR}$ was used to perform the analyses using the three-layer technique. The main geometric parameters and material properties of the notched steel plate in Fig. 1 are summarised in Table 1.

Since composite patches are located on both side of the plate, only $1 / 8$ of the specimen was meshed (Fig. 4) as a continuum medium. Since tensile loading is applied to the specimens, no variation of the stress intensity factor is expected over the thickness. Standard eight-noded shell elements were used for the adhesive layer and the composite patch, and plane stress elements were used for the steel plate.

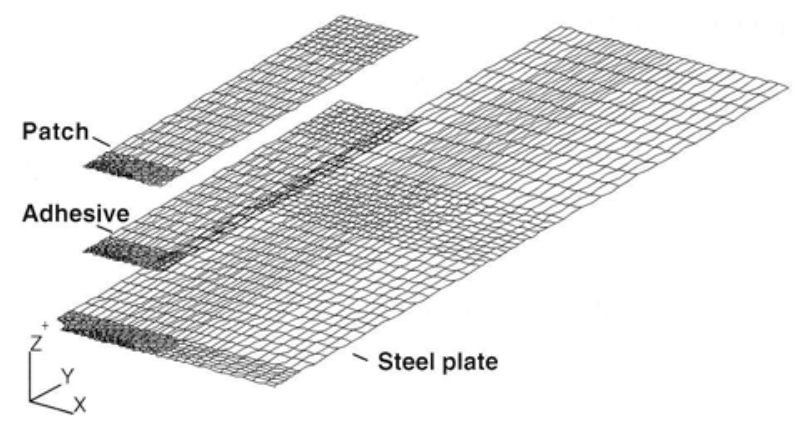

Fig. 4 1/8 of the three layer finite element model.
Based on the experimental evidence, the debond crack was assumed to lie in the plate-adhesive interface with a semi-elliptical shape (Fig. 5).

The finite element analysis is performed for a given delamination shape parameter $c / b$. The major semiaxis $b$ was assumed equal to the crack size a plus the dimension of the plastic zone at crack front in plate and was aligned with the crack path. The minor semiaxis $c$ was then located in a direction orthogonal to the crack one $^{3}$ (Fig. 5). No attempts were then done to model the delamination size growing in the finite element model. A parametric analysis was performed in order to investigate the sensitivity of the stress intensity factor level to variations in the patch stiffness $\left(E_{1}\right.$ and $b^{\mathrm{c}}$ ), adhesive thickness $b^{\mathrm{a}}$, strips pre-stress level $\sigma \pi$. and the size of the debonded region. The strain energy release rate, $G$, was computed by using the standard virtual crack extension method ${ }^{17}$ and converted into the stress intensity factor, $K$, by assuming plane stress for the local stress field near the crack tip and mode I crack opening: ${ }^{3}$

$K=\sqrt{G \cdot E}$

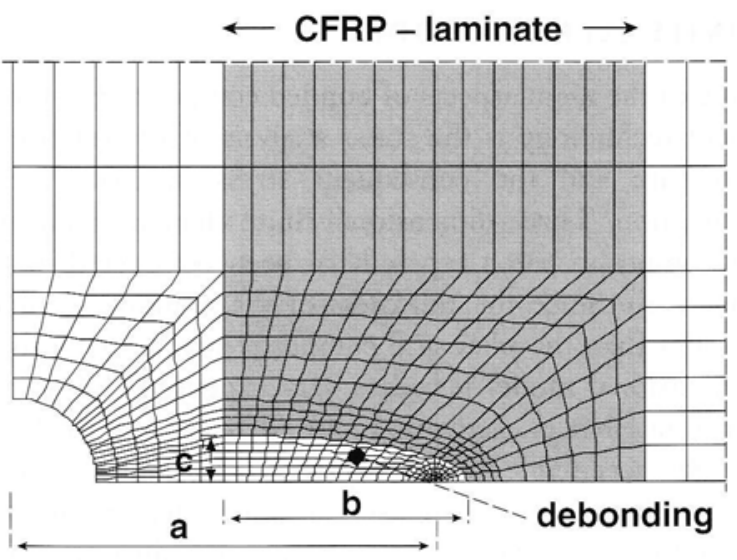

Fig. 5 Detail of the finite element model in the debonding region

\begin{tabular}{|c|c|c|c|c|}
\hline Layer & Length (mm) & Width (mm) & Thickness (mm) & Material properties \\
\hline Steel plate & 1000 & 300 & 10 & $E_{\mathrm{s}}=210 \mathrm{GPa}, v_{\mathrm{s}}=0.3$ \\
\hline Adhesive & 500 & 50 & 0.3 & $E_{\mathrm{a}}=714.14 \mathrm{MPa}, v_{\mathrm{a}}=0.32$ \\
\hline CFRP patch & 500 & 50 & 1.2 & $\begin{array}{l}E_{1}=174 \mathrm{GPa}, E_{2}=9 \mathrm{GPa} \\
v_{12}=0.28, G_{12}=G_{13}=4.5 \mathrm{GPa} \\
G_{13}=4.4 \mathrm{GPa}\end{array}$ \\
\hline
\end{tabular}
$(a=50 \mathrm{~mm})$.

Table 1 Material properties and dimensions 


\section{RESULTS AND DISCUSSION}

Figures 6-12 illustrate the results of the parametric analysis. The reference values of the model parameters are $E_{1}=174 \mathrm{GPa}, b^{\mathrm{a}}=0.3 \mathrm{~mm}, b^{\mathrm{c}}=1.2 \mathrm{~mm}$, an elliptical debonded region with $c / b$ equal to $1 / 5$ and no pre-stress $(\sigma \pi .=0)$ in the composite strips. The corresponding stress intensity factor values are normalised with respect to $\sigma_{y, \max } \cdot \sqrt{\pi \cdot a}\left(\sigma_{y, \max }=133 \mathrm{MPa}\right.$ is the maximum stress in the nominal section of the un-reinforced steel plate) and reported as function of the crack size a (the crack size is measured from the central axis of the plate and then includes the hole radius). Results show a different behaviour for short cracks, which are outside the strip area, compared to long cracks, which are partially covered by the patch. Figure 6 shows the stress intensity factor for notched plates reinforced by CFRP strips with and without pre-stress.

Without pre-stress, the effectiveness of the reinforcement is higher for long cracks compared to short cracks.
In particular for short cracks the reduction of the stress intensity factor is marginal and a pre-stress must be introduced in order to prevent crack propagation. In fact, in this case the patch reinforcement simply reduces the stress range in the steel plate. Since the stiffness of the steel plate is much larger than the composite strips one, a marginal reduction of the stress range is achieved. The effectiveness of the patch reinforcement is maximized for a long crack close to the external boundary of the strip. In this case, in fact, the patch covers a large amount of the crack and its plastic zone and then an additional significant reduction of the correction factor $Y$ (a) is achieved. pre-stress of the CFRP strips does not produce a reduction of the stress intensity factor range but a reduction of the stress ratio $R$ that promotes crack closure. As an example the application of a pre-stress $\sigma_{\mathrm{p}}=632 \mathrm{MPa}$ reduces the stress ratio to 0.03 (Fig. 6).

Since the patch stiffness is proportional both to the composite patch Young's modulus $E_{1}$ and the patch thickness $b^{\mathrm{c}}$, variations of these two parameters produce
Fig. 6 Normalised stress intensity factor vs. crack length for composite strips with and without pre-stress.
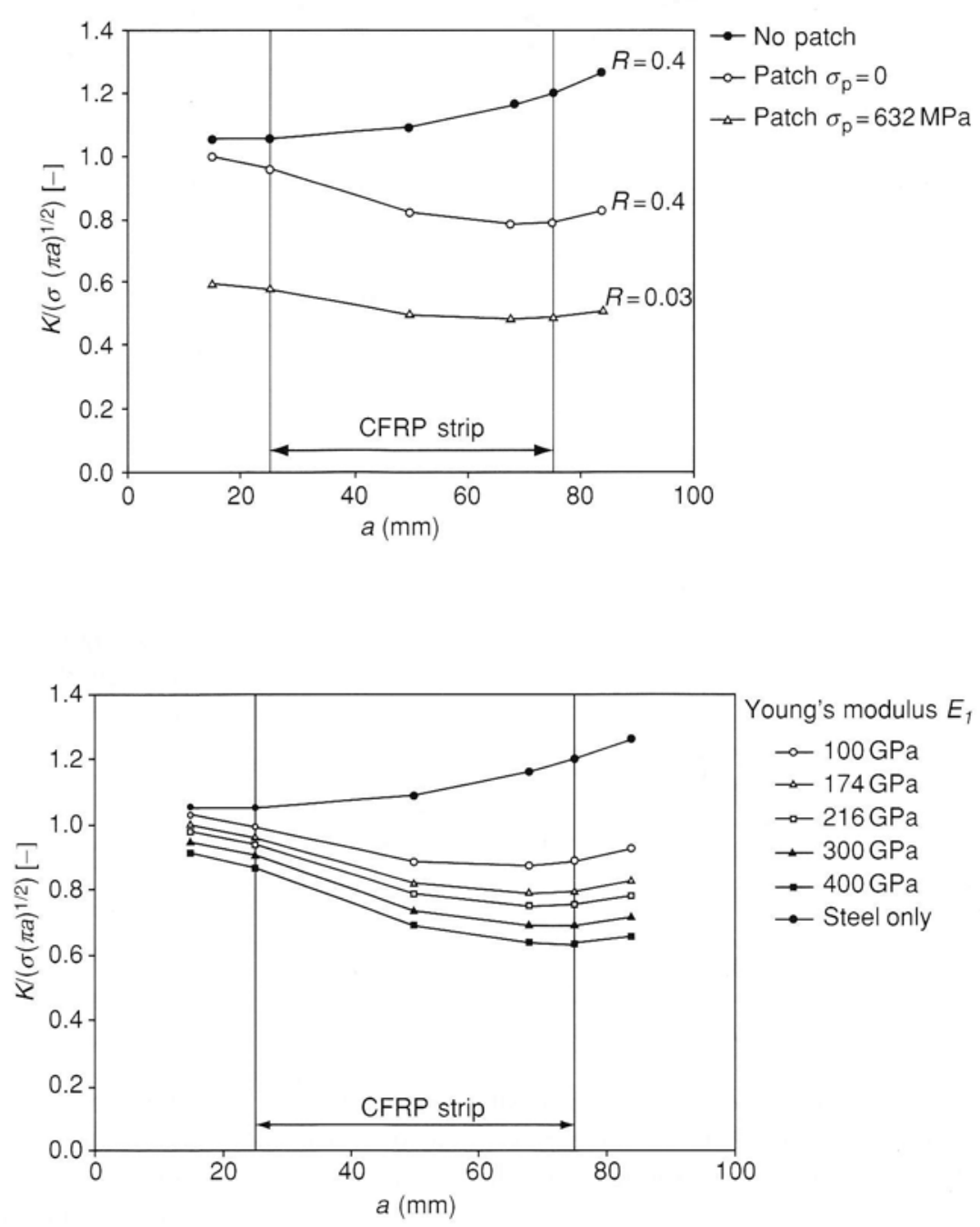

Fig. 7 Normalised stress intensity factor vs. crack length as function of the patch Young's modulus. 

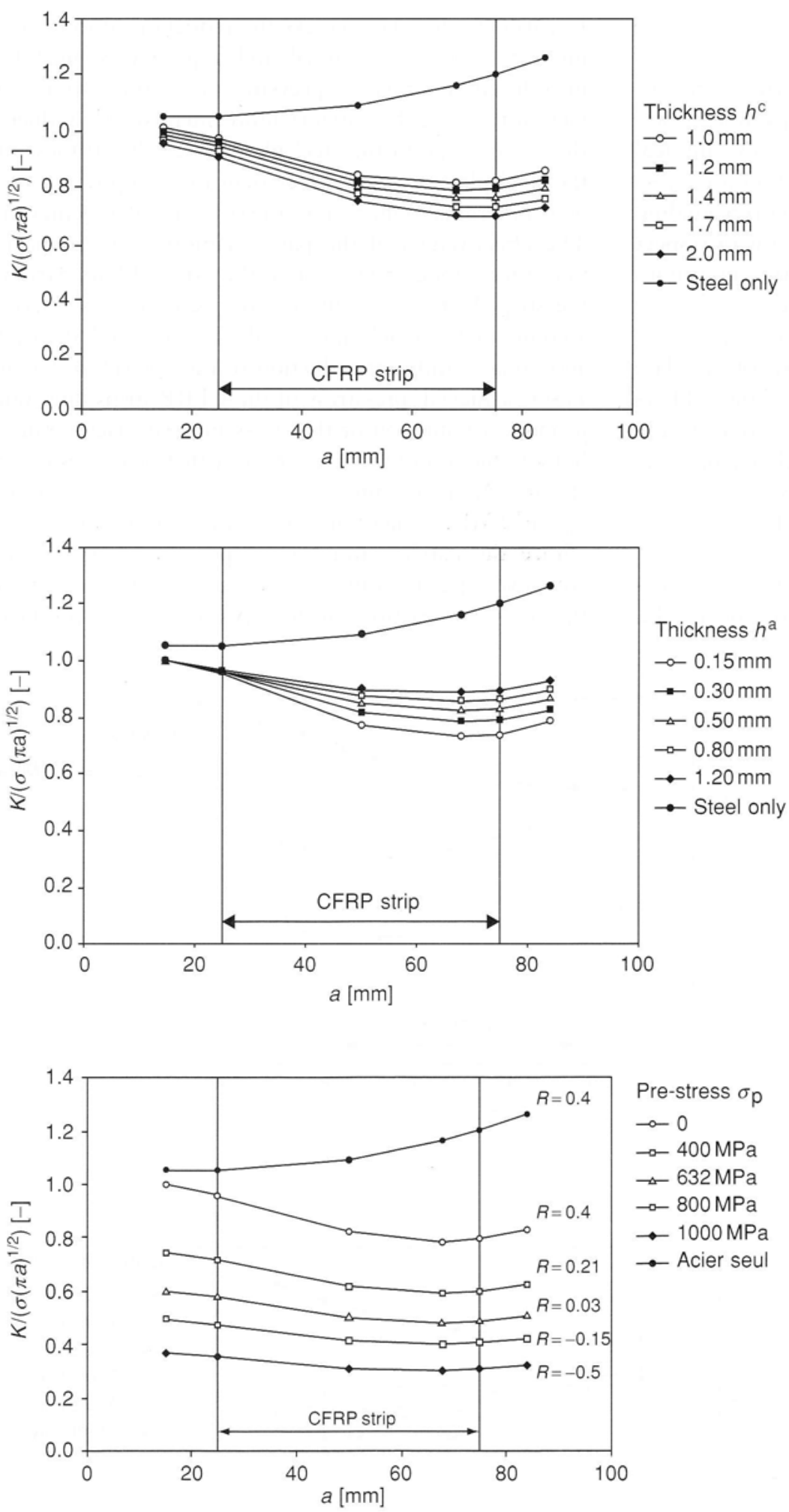

a similar effect on the stress intensity factor. Figure 7 depicts the sensitivity of the stress intensity factor to the composite patch Young's modulus $E_{1}$ in the fibre direction.
Fig. 8 Normalised stress intensity factor vs. crack length as function of the patch thickness.

Fig. 9 Normalised stress intensity factor vs. crack length as function of the adhesive thickness.
Fig. 10 Normalised stress intensity factor vs. crack length as function of the pretension level.

$$
\begin{aligned}
& \text { Pre-stress } \sigma_{\mathrm{p}} \\
& \multimap 0 \\
& \rightarrow-400 \mathrm{MPa} \\
& \rightarrow 632 \mathrm{MPa} \\
& \rightarrow-800 \mathrm{MPa} \\
& \rightarrow 1000 \mathrm{MPa} \\
& \rightarrow \text { Acier seul }
\end{aligned}
$$

The reduction of the stress intensity factor is more important for long cracks compared to short cracks. For long cracks, partially covered by the patch, CFRP strips modify the crack geometry by bridging the crack 
lips and this effect is more pronounced for stiff patch. For short cracks, the CFRP strips simply produce a reduction of the stress range. Figure 8 depicts the influence of the composite strip thickness $b^{\mathrm{c}}$.

Note that, in this case, due to patch shear deformation, the stress intensity factor decrement is less pronounced compared to the one produced by a variation of the composite patch Young's modulus $E_{1}$. Figure 9 illustrates the effect of the adhesive thickness on the stress intensity factor values.

Clearly, the effectiveness of the reinforcement decreases as the adhesive thickness increases. This is due to shear deformation of the adhesive layer. This effect is more important for long cracks where the capacity of the CFRP strips to bridge the crack lips is reduced by shear deformation of the adhesive layer. On the contrary, the adhesive has no influence on short cracks that are outside the patch area. The effect of the pre-stress level is reported in Fig. 10.

A pronounced reduction, in particular for short cracks, of the stress intensity factor is achieved by increasing the

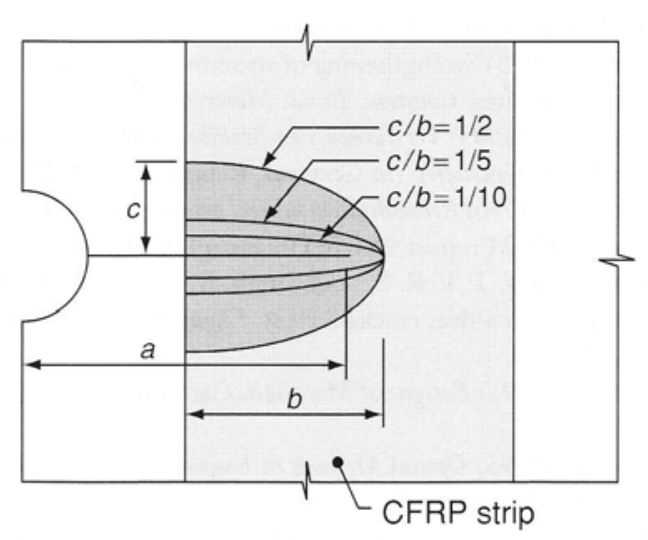

Fig. 11 Elliptical debond used in the parametric analysis. pre-stress value. Note that in this case the stress intensity factor range remains unchanged but the stress ratio is decreased, and even negative stress ratio is achieved as indicated in Fig. 10. This promotes crack closure effects that reduces the effective stress intensity factor range and then the corresponding crack growth rate.

The influence of the size of the debonded region is studied with reference to elliptical debond with different aspect ratio $c / b$ (Fig. 11).

Figure 12 illustrates the effect of the size of the debonded region on the stress intensity factor values.

The effect is more important for long cracks for which the crack bridging effect is reduced by the increment of the debonded area. On the contrary, the size of the debonded region has no effect on short cracks since, in this case, the debonded region does not influence the stress field at crack tip.

\section{CONCLUSIONS}

Experimental result shows that the application of prestress CFRP strip is a promising technique for the reinforcement of fatigue damaged steel section. In particular, it is appealing for riveted bridges built up at the beginning of the last century by non-weldable steel. This technique can be used to reduce or to stop crack propagation of existing cracks. Moreover, pre-stress of the CFRP strips prior to bonding introduces compressive stress, which prevent further cracking by promoting crack closure effect. Crack closure is a very important aspect since it reduces the effective stress intensity factor range and then decreases significantly the fatigue crack growth rate. Pre-stressing of the CFRP strips is mandatory in order to prevent further crack propagation of short cracks in steel elements.

Results of the sensitivity analysis clearly indicate a different effect of the pre-stress reinforcement on short cracks compared to long cracks. They show that the
Fig. 12 Normalised stress intensity factor vs. crack length as function of the debonded area.

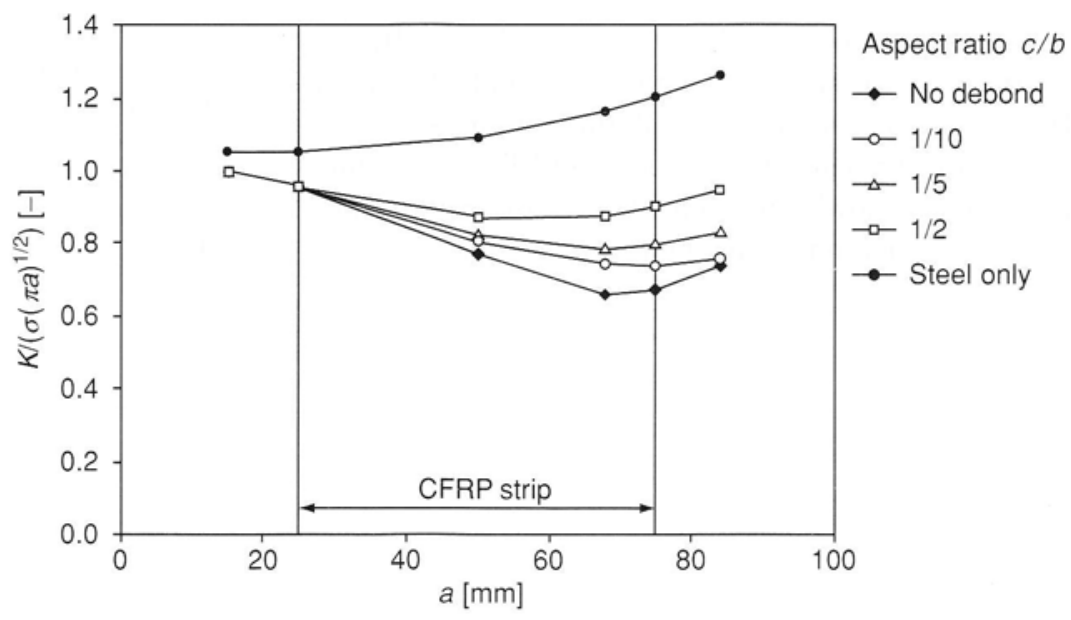


application of high stiffness pre-stress CFRP strips bonded perpendicular to the crack path modifies the crack geometry by bridging the crack lips. Pre-stress reduces the corresponding stress ratio and then promotes crack closure that reduces the fatigue crack growth rate.

For long cracks in steel elements, CFRP patches reduce the stress intensity factor range, even without pre-stress, since the patch covers the plastic zone and a large portion of the crack. For short cracks in steel elements, crack bridging effect by CFRP without pre-stress is negligible (Figs 7 and 8) since the cracks are outside the strip area.

Shear deformation of the adhesive layer has a significant effect of the effectiveness of the bonded reinforcement. Figure 9 shows that as the adhesive shear deformation increases with adhesive thickness, the effectiveness of the bonded reinforcement technique is reduced. Adhesive thickness effect is more important for long cracks compared to short ones since shear deformation reduces crack bridging.

Pre-stress of the composite strips is introduced to reduce the stress ratio in the cracked plate and then to promote crack closure. This phenomenon is very important for short crack since crack bridging has a negligible effect in this case.

Debond of the composite patch at the plate-adhesive interface plays an important role for long cracks (Fig. 12). It reduces the bridging effect of composite patch due to the deformation of the debonded patch. The corresponding increment of the stress intensity factor in the plate is similar, for long cracks, to the one produced by the reduction of the CFRP strips stiffness. Then, for long cracks, the influence of the debonded region cannot be discharged.

\section{Acknowledgements}

The financial support to the first author by the Italian Ministry of Instruction, University and Research (MIUR) and to the second and third authors by the Swiss National Science Foundation and EPFL Lausanne is gratefully acknowledged. Thanks are also expressed to Sika AG - Zürich for supplying composite materials.

\section{REFERENCES}

1 Bassetti, A., Nussbaumer, A. and Hirt, M. (March 2000) Crack repair and fatigue life extension of riveted bridge members using composite materials. In: Bridge Engineering Conference, Sharm, El-Sheikh, Egypt, 1, pp. 227-238.

2 Bassetti, A., Colombi, P. and Nussbaumer, A. (May 2000) Finite element analysis of steel members repaired by pre-stress composite patch. In: Proceedings IGF2000, CD-ROM, Bari, Italy.

3 Bassetti, A., Nussbaumer, A. and Colombi, P. (October 2000) Repair of riveted bridge members damaged by fatigue using CFRP materials. In: Advanced FRP materials for civil structures, Bologna, Italy, pp. 33-42.

4 Bassetti, A., Nussbaumer, A. and Hirt, A. (September 2000) Fatigue life extension of riveted bridge members using pre-stress carbon fibre composites. In: Steel structures of the 2000s, ECCS, Istanbul, pp. 375-380.

5 Bassetti, A. (2001) Application de lamelles pre-contraintes en fibres de carbone pour le renforcement d'elements de pont rivetes endommages par fatigue (in French), $\mathrm{PhD}$ Thesis, Swiss Federal Institute of Technology, EPFL.

6 Bassetti, A., Facchini, M. and Jacquot, P. (April 2001) Ameliorament de la tenue en fatigue de structures metalliques: evaluation par interferometrie speckle du procede de renforcement par lamelles composites (in French). In: Photomecanique 2001, Poiters, pp. 351-358.

7 Baker, A. A and Jones, R. (1988) Bonded repair of aircraft structures. Martinus-Nijhoff Publishers.

8 Meier, U. (1995) Strengthening of structures using carbon fibre/ epoxy composites. Construc. Build. Mater: 9, 341-351.

9 Deuring, M. (1993) Verstärken Von Stablbeton Mit Gespannten Faserverbundwerkstoffen (in German). Report 224, EMPA.

10 Ammar, N. (1996) Rebabilitation of steel bridge girder with graphite pultrasion. CCM report 96-26, University of Delaware.

11 Umamaheswar, T. V. R. S. and Singh, R. (1999) Modelling of patch repair to a thin cracked sheet. Engng Fract. Mech. 62, 267-289.

12 Suresh, S. (1991) Fatigue of Materials. Cambridge University Press.

13 Cloud, G. (1995) Optical Methods in Engineering Analysis. Cambridge University Press.

14 Ratwani, M. M. (1979) Analysis of cracked adhesively bonded laminated structures. ALAA F. 17, 988-994.

15 Sun, C. T. and Klug, J. (1996) Analysis of cracked aluminium plates repaired by bonded composite patches. $A L A A$ J. 34, 369-374.

16 Naboulsi, S. and Mall, S. (1996) Modelling of a cracked metallic structure with bonded composite patch using the three layer technique. Compos. Struct. 35, 295-308.

17 Parks, D. M. (1977) The virtual crack extension method for non-linear material behaviour. Comput. Meth. Appl. Mech. Engng $12,353-364$. 